\title{
O nivel de conhecimento dos estudantes de ciências biológicas em microbiologia do solo
}

\section{The level of knowledge of biological sciences students in microbiology soil}

\author{
${ }^{1}$ Rogerio Custódio Vilas Bôas \\ ${ }^{1}$ Antônio Fernandes Nascimento Júnior \\ ${ }^{2}$ Fatima Maria de Souza Moreira fmoreira@dcs.ufla.br
}

\section{RESUMO}

As Licenciaturas em Ciências Biológicas devem qualificar seus graduandos para que possam inserir em suas futuras práticas pedagógicas temas atuais de relevância social e ambiental no sentido de valorizar a preservação e o bem estar de todas as formas de vida. Os conteúdos da área de Microbiologia do Solo possuem potencial para que diferentes questões sociais e ambientais sejam abordadas na educação básica. Estes conhecimentos específicos devem fazer parte do repertório dos futuros professores. Assim, o objetivo deste trabalho foi avaliar o nível de conhecimento em Microbiologia do solo dos estudantes formandos em Ciências Biológicas de uma universidade pública e outra particular. A coleta de dados ocorreu através de um questionário composto por dez questões objetivas, que abordavam a importância e a aplicação de diversos processos realizados pelos micro-organismos do solo. As análises das respostas evidenciaram que alguns estudantes concluintes do curso de Licenciatura em Ciências Biológicas apresentaram dificuldades em determinados conteúdos específicos da Microbiologia do Solo, e que estes têm uma formação inicial insuficiente para trabalharem este conteúdo com seus futuros estudantes. Os cursos de formação inicial e continuada devem ficar atentos aos avanços científicos e as necessidades da sociedade onde estão inseridos.

Palavras-chaves: Formação de professores, educação científica, ensino de microbiologia.

\begin{abstract}
ABSTRAT
The courses of graduation in Biological Sciences must qualify their graduates that they will be able to insert in future pedagogical practices current themes of social and environmental relevance, to value the preservation and well being of all life forms. The contents in the Microbiology Soil have potential in order to different social and environmental questions be broached in basic education. These specific knowledges must take part of a repertory of future teachers. So, the aim of this study was to evaluate the level of knowledge in Soil Microbiology of the students in process of graduation in Biological Sciences in one public and other private university. The data were collected through a questionnaire consisting of ten objective questions, which broached the importance and application of several processes performed by the soil micro-organisms. The analysis of the answers showed that some students that were concluding the course of graduation in Biological Science presented difficulties in some specific contents of Soil Microbiology, and they have an insufficient initial instruction courses to work this content with their future students. The initial and continuing education courses should be attentive to scientific advances and the necessities of the society in which they live.
\end{abstract}

Keywords: Teacher, science education, basic education.

1 Universidade Federal de Lavras.

2 Universidade Federal de Lavras - Depto. de Ciência do Solo DCS/UFLA - Caixa Postal 3037 - CEP 37200-000 - Lavras, MG. 


\section{INTRODUÇÃO}

As contribuições científicas esperadas de um maior conhecimento sobre a diversidade de micro-organismos são extensas, entre outras, a melhor compreensão das funções exercidas pelas comunidades microbianas nos ambientes e o conhecimento das suas interações com outros componentes da biodiversidade (COLWELL, 1997). Os benefícios econômicos e estratégicos estão relacionados com a descoberta de micro-organismos potencialmente exploráveis nos processos biotecnológicos para: novos agentes terapêuticos e antibióticos, produtos químicos, probióticos, polímeros e enzimas para aplicações industriais e tecnológicas, biolixiviação e biorremediação de poluentes e recuperação de minérios. Outros benefícios incluem o prognóstico e prevenção de doenças emergentes em seres humanos, animais e plantas, e a otimização da capacidade microbiana para a fertilização dos solos e despoluição das águas (HUNTER-CEVERA, 1998).

Pesquisas comprovam que os micro-organismos do solo desempenham papel fundamental nos ecossistemas terrestres, porém sua importância ainda é pouco reconhecida e a grande parte da população os tem visto mais como causadores de doenças. A maioria dos materiais didáticos (livros e apostilas) adotados para o ensino de Biologia no Ensino Médio não aborda esse tema, o que constitui uma negligência grave, pois os estudantes não são conscientizados da importância dos processos realizados pelos micro-organismos do solo para manutenção dos ecossistemas agrícolas e naturais (VILAS BOAS; MOREIRA, 2012).

Como exemplo de importantes processos realizados pelos micro-organismos do solo, podemos citar a utilização de Bactérias Fixadoras de Nitrogênio e dos Fungos Micorrízicos Arbusculares na recuperação de áreas degradadas, na conservação dos solos e também na produtividade agrícola. As degradações ambientais ainda são pouco percebidas pela maioria das pessoas e isso aponta o limitado conhecimento de parte da sociedade sobre elementos que compõem o meio ambiente, assim como suas interações (VILAS BOAS; MOREIRA, 2012).

É inegável a importância da educação e das inovações científicas na vida das pessoas, o professor e a escola têm papel fundamental nessa ação. Importante ressaltar que os estudantes possuem visão estereotipada sobre a natureza da Ciência que pode estar relacionada a uma série de fatores, entre eles: visão distorcida da Ciência apresentada pela mídia, pouco contato dos estudantes com veículos de divulgação científica e formação inadequada dos professores.

No que diz respeito aos professores, várias pesquisas indicam que a concepção de Ciência que possuem influência, de maneira decisiva, na forma como apresentam o conhecimento científico em sala de aula (CHINELLI et al., 2010).

Neste contexto os professores não são preparados em seus cursos de graduação ou em cursos de formação continuada para o ensino de Microbiologia do Solo no Ensino Médio, o que vem acarretando falhas na formação e conscientização dos jovens do Ensino Médio sobre os importantes processos realizados pelos micro-organismos do solo.

No Brasil, o tema “formação do professor de ciências" está constantemente em discussões que envolvem a questão da melhoria do ensino de ciência, evidenciada pelo crescente interesse em pesquisa com a formação inicial e continuada de professores (CUNHA; KRASILCHIK, 2000). Acredita-se que, quanto mais cedo os estudantes graduandos de um curso de licenciatura em Ciências Biológicas realizarem sua inserção nas escolas onde atuarão como profissionais no futuro, mais e melhores contribuições serão proporcionadas ao processo ensino-aprendizagem. Concomitantemente, os professores já inseridos na atividade docente, com os quais haverá intercâmbio de saberes, serão estimulados a repensar sua prática pedagógica, o que representará, também, contribuições para a dinamização do processo ensino-aprendizagem em ciências (SCHEID et al., 2009). 
Dentre as críticas referentes à formação de professores destaca-se à separação entre conhecimentos científicos e conhecimentos profissionais docentes; conhecimento acadêmico e realidade escolar; disciplinas específicas da área e disciplinas pedagógicas, ou entre formação científica e formação pedagógica (SCHÖN, 1983; NÓVOA, 1992; MARCELO, 1999; TARDIF, 2000; TARDIF, 2009). Certificamos que o mesmo vem acontecendo com o conteúdo de Microbiologia do Solo no Ensino Médio, talvez pela falta de domínio e de atualização dos professores esse conteúdo não é abordado nesse nível de ensino.

É imprescindível que o professor reelabore os conhecimentos científico-biológicos, pois estes não são acessíveis e nem apropriáveis de forma simples e direta pelos estudantes, tais conhecimentos devem ser transformados pedagogicamente em conteúdos de ensino. Para que os professores exerçam esse papel de mediador, entre os saberes e conhecimentos a serem desenvolvidos por eles na sua formação inicial (graduação), estão os relativos ao o quê, como e por que ensinar os conteúdos que estarão sob suas responsabilidades (SOARES, 2009).

Pesquisas evidenciam que geralmente os professores de Ciências/Biologia atuam meramente como transmissores mecânicos de conteúdos de livros didáticos, não se envolvendo em práticas pedagógicas inovadoras e repassando aos estudantes fatos, informações, conceitos de maneira assistemática e descontextualizada histórica e socialmente (FURIÓ MÁS, 1994; CARVALHO; GIL PÉREZ, 1993; MALDANER, 2000). O reflexo desta prática pedagógica, nos educandos é apenas a memorização dos conteúdos. E ainda, os conteúdos não são atualizados cientificamente, como vem acontecendo com a Microbiologia do Solo no Ensino Médio.

É inquestionável a importância da ciência na vida das pessoas, o professor é o mediador indispensável para articular o conhecimento de forma contextualizada e sistemática entre os estudantes.

Há no mundo fortes influências da ciência e da tecnologia, e é importante o professor estar sempre atualizado para que possa interagir com desenvoltura diante de tantas inovações que fazem parte do nosso dia-a-dia. Atualmente a Biologia tem destaque entre as ciências de ponta, e os avanços científicos nesta área marcam sensivelmente a sociedade, desde o século passado. Desse modo, o ensino de Biologia é de extrema relevância para a vida de todo cidadão, e as escolas têm a função de contribuir para que esse conhecimento chegue a todas as pessoas. Tem crescido nos últimos tempos as pesquisas que visam superar o modelo tradicional de ensino, preparando os estudantes para atuarem como cidadãos questionadores, críticos e capazes de interferirem de maneira positiva na sociedade onde vivem (KRASILCHIK, 2004).

Os cursos de formação de professores de Biologia precisam rever as metodologias de ensino, considerando-as de forma crítica e participativa, pois a metodologia utilizada pelo professor, o domínio do conhecimento específico, a busca por atualizações científicas de sua área e áreas afins, e a relação deste com os educandos são decisivas no processo ensino-aprendizagem (GIL-PÉREZ, 1996).

Embora considerasse a necessidade de articulação entre os conteúdos específicos e as metodologias de ensiná-los, o presente artigo realiza um recorte analítico em torno do repertório sobre conteúdos da área de microbiologia do solo. Sendo assim, o objetivo do presente trabalho foi analisar o nível de informação dos estudantes concluintes do curso de Ciências Biológicas de duas Universidades, uma Federal e outra particular da cidade de Lavras MG, em questões fundamentais do conteúdo de Microbiologia do Solo.

\section{METODOLOGIA}

Foi elaborado um questionário do tipo fechado, composto por dez perguntas divididas em dois grupos, caracterização dos estudantes (questões 1, 2 e 3) e conhecimentos específicos de Microbiologia do Solo (questões de 4 a 10). As questões foram compostas por quatro alternativas sendo apenas uma delas correta (em anexo). 
O projeto do presente trabalho foi aprovado pelo Comitê Nacional de Ética em Pesquisa com Seres Humanos (número do processo: CAAE 02230512.0.1001.5148, e o parecer favorável de número 44936). O Comitê de Ética em Pesquisa (CEP) é o órgão institucional que tem por objetivo proteger o bem-estar dos indivíduos pesquisados. É um comitê interdisciplinar, constituído por profissionais de ambos os sexos, além de pelo menos um representante da comunidade, que tem por função avaliar os projetos de pesquisa que envolvam a participação de seres humanos. Sua missão é salvaguardar os interesses dos sujeitos da pesquisa em sua integridade e dignidade e para contribuir no desenvolvimento da pesquisa dentro de padrões éticos. Após esse trâmite, a pesquisa foi autorizada pelas coordenadoras dos cursos de licenciatura em Ciências Biológicas das duas universidades.

Todos os estudantes que participaram da pesquisa responderam o questionário e preencheram o Termo de Consentimento Livre e Esclarecido para participação na pesquisa, uso da imagem, voz e textos com fins de divulgação científica. Depois de preenchidos, os questionários foram devolvidos aos autores da pesquisa para análise dos dados. É pertinente informar que toda a identificação de pessoa jurídica e/ou de pessoa física foi sigilosamente guardada.

O curso de Licenciatura em Ciências Biológicas da universidade particular é ministrado dentro de uma estrutura com longa experiência em cursos da área de saúde e conta com um quadro de 18 docentes, sendo oito doutores e 10 mestres, graduados nos mais diversos cursos (física, matemática, odontologia, ciências biológicas licenciatura e bacharel, psicologia, pedagogia, agronomia, filosofia, letras, fisioterapia).

Na universidade pública o curso de Licenciatura em Ciências Biológicas conta com um quadro de 45 docentes, sendo 44 doutores, e um mestre, graduados nos mais diferentes cursos (Oceanologia, Ecologia, Agronomia, Ciências Biológicas licenciatura e bacharelado, Física, História Natural, Nutrição, Engenharia Florestal), a maioria é graduada em Ciências Biológicas.

O questionário foi aplicado nos horários das aulas com o maior número de estudantes do último ano do curso de Licenciatura em Ciências Biológicas.-

Foi feita uma análise quantitativa das respostas, buscando identificar o perfil e o nível de conhecimento dos graduandos em torno do tema Microbiologia do Solo.

\section{RESULTADOS E DISCUSSÃO}

\section{Caracterização dos estudantes}

As três primeiras questões do questionário foram elaboradas com objetivo de caracterizar e traçar um perfil dos estudantes. Nas universidades pública e particular foram 17 estudantes (total) que responderam o questionário durante as aulas da disciplina de Estágio Docência em Biologia, por contar com maior número de estudantes concluintes do curso. Do total desses estudantes onze se encontravam na faixa etária entre 20 a 24 anos e seis entre 25 a 29 anos. Entre os estudantes, quatorze pretendem atuar na área acadêmica de educação e pesquisa e apenas três manifestaram o interesse em atuar como professores no Ensino Fundamental e Médio.

De acordo com estudo realizado pela Fundação Victor Civita (FVC) e Instituto Nacional de Estudos e Pesquisas Educacionais Anísio Teixeira (INEP) em 2010, apenas 2\% dos jovens que estão no $3^{\circ}$ ano do Ensino Médio querem cursar Pedagogia ou alguma licenciatura.

No trabalho realizado por Louzano et al (2010) eles concluem que, dos estudantes que fizeram ENEM em 2005 e responderam o questionário socioeconômico, a minoria manifestou o interesse em ingressar na carreira 
de magistério e que estes pertenciam ao grupo com pior desempenho na escola básica e são estudantes vindos de famílias com renda inferior a três salários mínimos.

Além do perfil dos que são atraídos para a carreira docente, há que se levar em conta também a qualidade da formação oferecida a esses futuros professores em seus cursos de licenciaturas nas faculdades, institutos e universidades.

Para Hammond (2000) a formação e certificação de professores têm forte correlação com o desempenho dos estudantes da educação básica e destes com a sociedade onde vivem.

A universidade e demais instituições de ensino têm o dever de levar o conhecimento produzido em seus campus até as comunidades onde estão inseridas. A boa formação de professores e de outros profissionais cumpre parte do papel social que as universidades têm. Quanto à formação de professores Rice (2003) concluiu que disciplinas que focam em conteúdos destinados a desenvolver habilidades essenciais nos professores, tais como metodologias de ensino, gestão da sala de aula, avaliação escolar e desenvolvimento curricular, contribuem para a eficácia do trabalho docente somente quando combinadas com o conhecimento sólido do conteúdo a ser ensinado. Portanto, foco em disciplinas mais práticas associadas ao domínio do conteúdo parece ser o mais importante.

Portanto o domínio de conteúdo priorizando o que é significativo e relacionado com o dia-a-dia do estudante pode tornar o aprendizado mais concreto. O ideal seria que o ensino de Microbiologia do Solo fosse baseado nesses critérios, fazendo com que professores e estudantes do Ensino Médio se conscientizem dos importantes processos realizados pelos micro-organismos do solo.

Do total de estudantes (17) que responderam o questionário pôde-se notar a dominância do gênero feminino com apenas quatro do gênero masculino, sendo evidente a predominância feminina na docência.

Uma pesquisa feita pela Confederação Nacional dos Trabalhadores em Educação (CNTE), e pelo INEP publicada em 2004, mostra um perfil dos professores da educação básica em dez estados do Brasil (Tocantins, Espírito Santo, Rio Grande do Norte, Paraná, Alagoas, Mato Grosso, Piauí, Minas Gerais, Goiás e Rio Grande do Sul). De acordo com os dados dessa pesquisa, $83 \%$ dos professores que estão atuando nas escolas desses estados são do gênero feminino. Em outra pesquisa realizada pela Fundação Carlos Chagas em 2005, evidencia que a participação das mulheres na educação superior no Brasil surpreende não apenas pelo número de matrículas de graduação, mas também pela crescente presença no corpo docente, nos níveis mais elevados de titulação. De acordo com os dados apresentados, o número de professores do gênero masculino cresceu 67,9\% de 1996 a 2003, o de professoras aumentou em 102,2\%.

Dados do INEP e FVC em 2010 mostram que o ingresso de estudantes nas universidades e faculdades para os cursos de Licenciaturas é uma escolha de poucos. Além disso, os poucos que optam por esses cursos, logo se veem desmotivados a continuarem seu curso.

O número de estudantes que se inscrevem nos cursos de Licenciaturas, vem diminuindo a cada ano. A sociedade, por valorizar cursos com maior status social, impulsiona os novos universitários a escolherem cursos que em muitos casos não são de sua preferência.

Uma grande consequência disto é a formação de profissionais frustrados e sem qualquer perspectiva.

Uma das hipóteses pela falta de profissionais relaciona-se ao fato de que a remuneração oferecida pelo mercado é insuficiente para a sustentação dos professores, levando-os a trabalharem mais de um período. Sendo assim, de acordo com Floriani (2002), os licenciados são levados a buscar outras áreas que lhes proporcionem uma renda mensal mais atrativa e consequentemente compromete sua dedicação como professor. 
Esses fatores justificam o número reduzido de estudantes concluintes nos cursos de licenciatura em Ciências Biológicas das duas universidades, e destes apenas alguns irão atuar como professores nos ensinos Fundamental e Médio.

\section{Análise das respostas dos estudantes às questões de Microbiologia do Solo}

As questões de quatro a dez foram elaboradas para avaliarem o desempenho dos estudantes em Microbiologia do Solo. Abordavam vários processos de importância agrícola, ambiental ou industrial realizados pelos micro-organismos do solo.

Na questão quatro aborda-se a importância do nitrogênio para os seres vivos e o processo de Fixação Biológica desse elemento. Para resolver a questão o estudante tinha que apresentar conhecimentos sobre os micro-organismos fixadores de nitrogênio, ou seja, que apenas alguns procariotos são capazes de realizar esse processo. Lembrando que, os fungos são desprovidos do sistema enzimático da nitrogenase, por isso são incapazes de fixar o nitrogênio atmosférico, erro cometido por $44 \%$ dos estudantes de Ciências Biológicas pesquisados.

Esse processo é um dos mais importantes realizados pelos micro-organismos do solo, sendo esse conhecimento fundamental para compreender a sustentabilidade dos ecossistemas e algumas alternativas de produção agrícola sustentável. Nesta questão os estudantes da universidade pública obtiveram melhor desempenho do que os estudantes da universidade particular.

A análise da questão cinco mostrou que os estudantes da universidade particular foram melhores que os da universidade pública com $75 \%$ de acertos. Esta questão abordava várias características físicas químicas e biológicas do húmus, que os estudantes tinham que conhecer. Sendo o húmus um componente muito importante da composição do solo, é imprescindível para o professor recém-formado compreender importância do seu papel no meio ambiente e trabalhar este tema com seus estudantes.

A questão seis abordava a produção de vários metabólitos produzidos pelos micro-organismos do solo e que muitos têm aplicações na fabricação de fármacos, controle biológico dentre outros. Foram citados vários fitorreguladores para que os estudantes os relacionassem com algumas alterações no desenvolvimento vegetal. Os estudantes da universidade particular não acertaram essa questão. Já os estudantes da universidade pública tiveram 25\% de acerto para esta questão.

Os estudantes das universidades pública e particular tiveram o mesmo desempenho na questão sete. Esta questão refere-se às várias interações ecológicas que ocorrem entre os micro-organismos do solo, e que muitos deles produzem inibidores metabólitos de grande especificidade e potência para serem usados durante essas interações. Nesta questão o estudante tinha que identificar qual o tipo de relação ecológica eles são mais utilizados. O desempenho dos estudantes para essa questão foi o mesmo para as duas universidades ( $25 \%$ de acertos).

A questão oito apresentava vários grupos de micro-organismos do solo que são capazes de degradarem xenobióticos. Os estudantes tinham que entender o significado do termo xenobiótico e associá-lo a várias aplicações dos micro-organismos com diversos processos biotecnológicos. Na universidade pública, $50 \%$ dos estudantes pesquisados entenderam o significado do termo xenobiótico e a aplicação de alguns micro-organismos do solo nesse processo. Já na universidade particular os estudantes demonstraram desconhecer o processo e suas aplicações, ninguém acertou essa questão. Vale ressaltar que os xenobióticos são substâncias químicas estranhas a um organismo ou a um sistema biológico, estão presentes em detergentes, lubrificantes, fibras, plásticos, pigmentos, biocidas e outros produtos artificiais oriundos do mundo moderno. Essas substâncias, estranhas ao nosso organismo, são encontradas no solo, nos mananciais e nos alimentos (MOREIRA \& SIQUEIRA, 2006).

A questão nove afirmava que no solo existem micro-organismos que são capazes de solubilizar minerais contendo $\mathrm{P}, \mathrm{Ca}, \mathrm{K}, \mathrm{Mg}$ e outros elementos essenciais às plantas, tornando-os disponíveis para o crescimento 
vegetal. Os estudantes tinham que marcar dentre as alternativas, aquela que apresentava uma justificativa para o fato de Micro-organismos solubilizadores parecem ser mais abundantes na rizosfera de plantas. Os estudantes da universidade pública obtiveram melhor desempenho nessa questão, com $50 \%$ de acertos, já os da universidade particular foram $25 \%$ deles que acertaram a questão.

A questão dez foi elaborada com objetivo de verificar um erro muito comum, cometido não só entre os estudantes, mas também por professores e autores de livros didáticos, ao afirmarem que fungos fixam nitrogênio. Esta questão relata, de acordo com Moreira e Siqueira (2006), que algumas espécies de fungos associam-se às raízes de plantas por serem incapazes de realizar a fotossíntese e, assim, obtêm carbono e outros nutrientes da planta hospedeira. A associação com as raízes torna-se essencial para o ciclo daqueles que não possuem vida saprofílica. Essas associações são conhecidas como micorrizas, e vários estudos buscam conhecer as bases biológicas desse sistema e seu funcionamento.

Dentre os vários benefícios fornecidos por essa associação o estudante tinha que identificar que os fungos micorrízicos não são capazes de fixarem nitrogênio atmosférico. A maioria dos estudantes da universidade particular (62\%) acertou essa questão, reconhecendo que fungos micorrízicos não fixam nitrogênio. Na universidade pública foram $39 \%$ dos estudantes que acertaram a questão. Os resultados do desempenho dos estudantes para essas questões estão apresentados na figura (1).

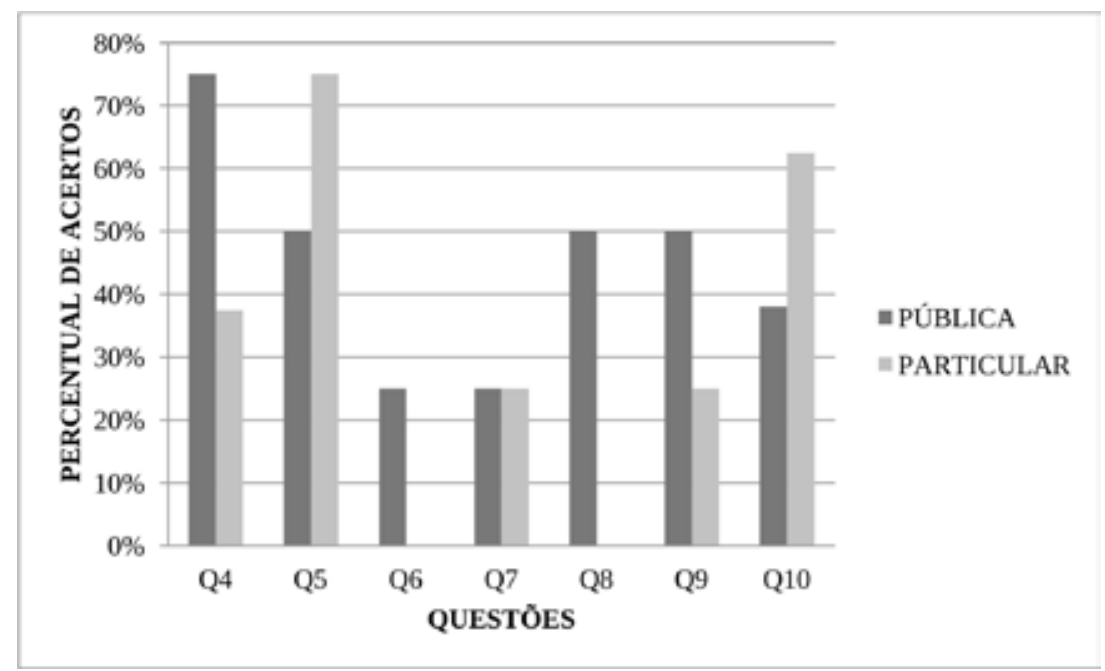

Figura1. Desempenho dos estudantes das universidades pública e particular concluintes do curso de Licenciatura em Ciências Biológicas nas questões de conhecimento específico em Microbiologia do Solo.

Esses resultados mostram que não basta universidades formarem os futuros professores, precisam ser criados programas de formação inicial e continuada, para que estes ao longo de sua carreira tenham acesso aos avanços científicos e tecnológicos da sua área de trabalho diminuindo assim a distância entre o conhecimento acadêmico e a educação básica.

No que consiste a formação inicial, Barzano (2002), ao investigar as Licenciaturas em Ciências Biológicas, mostra que os licenciandos poucas vezes são instigados a repensar o currículo em vigor e acabam por aderir ao currículo tradicional, pois já estão familiarizados a esse devido a toda uma trajetória escolar anterior. Sendo assim, sem muitas vezes questionar o porquê daqueles conteúdos a serem trabalhados e nem para que tipo de sociedade esse conteúdo interessa, os recém formados irão perpetuar uma determinada visão de ciência.

De acordo com Scheid et al. (2009), é de extrema importância a aproximação entre os acadêmicos e pesquisadores das universidades com as escolas de educação básica, como forma de promover um maior inter- 
câmbio e discutir subsídios teórico-metodológicos que possam contribuir para a melhoria da formação inicial e da prática docente.

O professor, precisa estar preparado e atualizado continuamente, não apenas nos conteúdos específicos, mas também nas questões pedagógicas e epistemológicas mais amplas, no caso particular do conhecimento científico (SCHEID et al. 2009).

Diante de tal cenário é extremamente importante que se invista cada vez mais em cursos de formação inicial presenciais para que eles aumentem a sua capacidade de formar professores. De acordo com o censo realizado em 2003 pelo INEP/MEC evidenciou que grande parte dos estudantes dos cursos de formação de professores são estudantes de classe média e oriundos de escolas públicas. São estudantes que têm uma base muito precária dos conhecimentos gerais e da língua portuguesa e a maioria abandona no primeiro e/ou segundo ano do curso porque não conseguem acompanha-lo e também porque precisam trabalhar (GOBARA; GARCIA, 2007). Esse fato torna-se mais evidente nos cursos das universidades privadas.

É importante salientar que a dificuldade dos estudantes se auto sustentarem durante o curso, a baixa expectativa de renda em relação à futura profissão, a falta de expectativa de melhoria salarial somado ao declínio do status social da profissão fazem com que os cursos de licenciatura, tanto em instituições públicas como privadas, vivam em constante crise (GOBARA; GARCIA, 2007).

\section{CONCLUSÕES}

A maioria dos estudantes de graduação em Ciências Biológicas das duas instituições pesquisadas apresenta deficiências quanto ao preparo em seus cursos para trabalharem o conteúdo de Microbiologia do Solo na escola, o que provavelmente vem acontecendo em outras instituições do Brasil.

Comparando os resultados dos estudantes da universidade pública com resultados da universidade particular, conclui-se que os estudantes da universidade pública estão sendo melhores preparados. Provavelmente porque a universidade pública possui melhor infraestrutura, com um departamento de Ciência do Solo e de Microbiologia, com longa experiência em pesquisa e ensino, o que pode estar refletindo positivamente na formação de seus docentes e discentes. Os estudantes da universidade particular se destacaram em algumas questões específicas.

A melhoria da qualidade do ensino de Biologia no Ensino Médio está intrinsecamente ligada à discussão da formação de professores em favor de uma comprometida atualização científica, que efetivamente permita o desenvolvimento de habilidades e competências necessárias para o desenvolvimento da cidadania.

Acompanhar através de pesquisas o processo de formação e a atuação dos professores oriundos desses cursos passa a ser importante para orientar os debates envolvendo o ensino de ciências no país.

Conscientizar os futuros professores da importância dos micro-organismos do solo é fundamental para uma visão integrada dos diversos componentes do ecossistema. Essa tarefa deverá ser realizada pelos docentes dos cursos de licenciatura em Biologia.

\section{AGRADECIMENTOS:}

À Fapemig e Capes - Edital Fapemig 13/2012 pesquisa em educação básica acordo Capes-Fapemig processo: CBB-APQ-03532-12 pelo financiamento do projeto e pela bolsa de R.C. Vilas Boas e ao CNPq, pela bolsa de produtividade em pesquisa de F.M.S. Moreira. 


\section{REFERÊNCIAS}

BARZANO, M. A. L. O conteúdo de ensino nas disciplinas do curso de licenciatura em Ciências Biológicas. Coletânea do $8^{\circ}$ Encontro Perspectivas do Ensino de Biologia [CDRom]. São Paulo: FEUSP/EDUSP, (2002).

Ministério da Educação, Estatísticas dos Professores no Brasil (Instituto Nacional de Estudos e Pesquisas Educacionais, Brasília, 2003).

CHINELLI, M. V.; FERREIRA, M. V. S.; AGUIAR, L. E. V. Epistemologia em sala de aula: A natureza da ciência e da atividade Científica na prática profissional de professores de Ciências. Ciência \& Educação, v. 16, n. 1, pp. 17-35, 2010.

CUNHA, A. M. O; KRASILCHILK, M. A formação continuada de professores de ciências: percepções a partir de uma experiência, trabalho apresentado na $29^{a}$ REUNIÃO ANUAL ANPEd [seção Formação de Professores], Caxambu, 2000.

DE CARVALHO, A. M. P.; PÉREZ, D. G. Formação de professores de ciências: tendências e inovações. Cortez, 1993.

COLWELL, R. Microbial diversity: the importance of exploration and conservation. Journal of Industrial Microbiology and Biotechnology, 18:5, 302-307, 1997.

FLORIANI, J. V. Professor e Pesquisador: Exemplificação apoiada na matemática. ed.2. FURB, Blumenau, 2000.

FUNDAÇÃO CARLOS CHAGAS. Mulheres brasileiras, educação e trabalho. Disponível em: <http://www.fcc. org.br/mulher/series_históricas/mbet.html>. Acesso em: 4 out. de 2012.

FUNDAÇÃO VICTOR CIVITA. A atratividade da carreira docente no Brasil. Disponível em: http://www.fvc. org.br/estudos-e-pesquisas/2010/atratividade-carreira-docente-30689.shtml. Acesso em: 24 jun. de 2014.

FURIÓ MAS, C. J. Tendências actuales em la formación del profesorado de ciências.

GARRIDO, E. \& CARVALHO, A. M. P. Discurso em sala de aula: uma mudança epistemológica e didática In: Coletânea $3^{\text {a }}$ Escola de Verão. São Paulo, FEUSP, 1995.

GIL-PÉREZ, D. Orientações didáticas para a formação continuada de professores de ciências. Formação continuada de professores de Ciênciasno contexto ibero-americano. Campinas. São Paulo: Autores Associados, 1996. In: Enseñanza de las Ciencias. Barcelona, v. 12, nº 2, pp. 188-199, 1994.

GOBARA, S. T.; GARCIA, J. R. B. As licenciaturas em física das universidades brasileiras: um diagnóstico da formação inicial de professores de física. Revista Brasileira de Física, v. 29, n. 4, p. 519-525, (2007)

HAMMOND, L. Teacher quality and student achievement: a review of state policy evidence. Education Policy Analysis Archives, v.8, n. 1, 2000.

Hunter-Cevera. The value of microbial diversity. Current Opinion in Microbiology, 1: 278-285, 1998.

INSTITUTO NACIONAL DE ESTUDOS E PESQUISAS EDUCACIONAIS ANÍSIO TEIXEIRA (INEP). Disponível em: <www.inep.gov.br> acesso em 13 de junho de 2014, 18h45min.

KRASILCHIK, M. O professor e o Currículo das Ciências. São Paulo: EPU: Editora da Universidade de São Paulo, 2004.

LOUZANO, P.; ROCHA, V.; MORICONI, G. M.; OLIVEIRA, R. P. D. O. Quem quer ser professor? Atratividade, seleção e formação docente no Brasil. Est. Aval. Educ., São Paulo, v. 21, n. 47, p. 543-568, set./dez. 2010 
MALDANER, O. A. A formação inicial e continuada de professores de química. Ijuí: Ed. UNIJUÍ, 2000.

MARCELO, C. G. Formação de Professores - para uma mudança educativa. Barcelona: Porto Editora, 1999.

MOREIRA, F.M.S. \& SIQUEIRA, J.O. Microbiologia e bioquímica do solo. 2.ed. Lavras, Universidade Federal de Lavras, 2006. 729p.

NÓVOA, António (Org.). Profissão professor. 2. ed. Portugal: Porto, 1999. 191 p.

PAGOTTO, M. D. S. A organização das licenciaturas: práticas atuais e perspectivas de mudanças. IN: Anais do IX ENDIPE, pp. 376-384, 1998.

PEREIRA, J. E. D. Formação de professores - pesquisa, representações e poder. Belo Horizonte: Autêntica, 2000.

RICE, J. Teacher quality: understanding the e' ectiveness of teacher attributes. Washington: Economic Policy Institute, 2003.

SCHEID, N. M. J.; SOARES, B. M.; FLORES, M. L. T. Universidade e Escola Básica: uma importante parceria para o aprimoramento da educação científica. R. B. E. C. T., vol 2, núm 2, mai./ago. 2009.

SCHNETZLER, R. P. O professor de ciências: problemas e tendências de sua formação. In: SCHNETZLER, R. P. e ARAGÃO, R. M. R. (orgs.). Ensino de Ciências: fundamentos e abordagens. Piracicaba: CAPES/UNIMEP, 2000.

SCHÖN, D. A . The Reflective Practitioner: How Professionals Think in Action. Basic Books, New York, 1983.

SOARES, E. C. Professores de Ciências e Química: O que revelam os trabalhos do GT formação de professores da ANPED de 2000 a 2008. In: IX Congresso Nacional de Educação - EDUCERE. III Encontro de Psicopedagogia. 26 a 29 de outubro de 2009. PUCPR.

SOUZA, C. A. Formação Docente no Contexto Escolar: contribuições da reconstrução curricular via Abordagem Temática. ALEXANDRIA Revista de Educação em Ciência e Tecnologia, v.4, n.2, p.83-107, novembro 2011.

TARDIF, M. Saberes profissionais dos professores e conhecimentos universitários: elementos para uma epistemologia da prática profissional dos professores e suas consequências em relação à formação para o magistério. Revista Brasileira de Educação. ANPED, nº 13, pp. 5-24, 2000.

TARDIF, Maurice; LESSARD, Claude. O trabalho docente: elementos para uma teoria da docência como profissão de interações humanas. 5. Ed Petrópolis: Vozes, 2009. 317 p.

VILAS BOAS, R. C.; MOREIRA, F. M. S. Microbiologia do Solo no Ensino Médio de Lavras, MG. R. Bras. Ci. Solo. 36:295-306, 2012. 


\title{
ANEXO
}

\section{Questionário aplicado}

\section{QUESTIONÁRIO DOS ESTUDANTES - “CONHECIMENTO DOS ESTUDANTES DO ÚLTIMO PE- RÍODO DE CIÊNCIAS BIOLÓGICAS EM MICROBIOLOGIA DO SOLO”}

\author{
Prezado (a) alunos (a),
}

Este questionário faz parte da coleta de dados que fornecerá informações para direcionar a elaboração de um curso de formação continuada em Microbiologia do Solo, a ser ministrado aos professores do Ensino Médio da rede pública, na Universidade Federal de Lavras.

Leia cada questão e dê a resposta que melhor traduza seu pensamento.

Suas respostas são confidenciais, não precisa se identificar.

Obrigado pela contribuição.

\section{INSTRUÇÕES PARA O PREENCHIMENTO}

Identifique sua resposta com um $\mathbf{X}$ dentro da caixa, que se encontra na frente das opções.

\section{Gênero.}
a) Masculino
b) Feminino.

2. Idade.
a) De 20 a 24
b) De 25 a 29
c) De 30 a 35
d) De 39 a 40
e) 41 anos ou mais

3. No decorrer do curso de Licenciatura em Ciências Biológicas já é possível você vê possibilidade de atuar (como):
a) Professor do Ensino Fundamental - (5 ${ }^{\circ}$. ao $9^{\circ}$. ano).
b) Professor do Ensino Médio.
c) Professor do Ensino Superior.
d) Na área de pesquisa, somente.
e) Na área de Educação e pesquisa.
f) Outros. 


\section{ABAIXO ESTÃO ALGUMAS QUESTÕES OBJETIVAS SOBRE MICROBIOLOGIA DO SOLO, LEIA- -AS COM ATENÇÃO E IDENTIFIQUE A ALTERNATIVA CORRETA.}

4. O Nitrogênio é um elemento indispensável para os seres vivos. Apesar disso, ele não é utilizado de forma direta por estes, com exceção de alguns micro-organismos que conseguem realizar um processo denominado de "Fixação Biológica do Nitrogênio". Esse processo é realizado apenas pelos micro-organismos:
a) Fungos, cianobactérias e vírus.
b) Fungos, bactérias e cianobactérias.
c) Micorrizas, cianobactérias e algas.
d) Bactérias, cianobactérias.

5. No enfoque da microbiologia funcional do solo, o húmus pode ser considerado um subproduto das transformações que os materiais orgânicos sofrem no solo. Mesmo com os recursos da Química Moderna, a estrutura molecular das substâncias húmicas é ainda pouco conhecida e assunto de muitos estudos, especulações e controvérsias. Sobre os principais efeitos potenciais do húmus no solo podemos considerar, exceto:
a) Melhora as condições físicas como agregação, aeração, retenção de umidade e permeabilidade.
b) Aumenta a superfície específica e efeito tampão, conferindo maior estabilidade ao solo.
c) Atua como fonte de doenças para a maioria dos organismos do solo.
d) Atua como reservatório de N, P, S e micronutrientes.

6. Os micro-organismos do solo sintetizam milhares de metabólitos que atuam nas interações microbianas e no crescimento e desenvolvimento das plantas. São conhecidos mais de $\mathbf{1 0 . 0 0 0}$ produtos de interesse comercial como fármacos, toxinas, fitorreguladores, agentes de biocontrole, enzimas e polissacarídeos. Entre os fitorreguladores podemos citar: etileno, auxinas, citocininas, ácido giberélico, fusárico, abcísico, além de outros. Através desses fitorreguladores os micro-organismos podem exercer nas plantas,
a) melhora nas condições de sustentação e fixação, pois alguns influenciam o crescimento das raízes.
b) menor resistência aos patógenos, uma vez que alguns fitorreguladores inibem a nutrição deixan- do-as mais vulneráveis à ataques de parasitas.
c) em condições elevadas danos morfológicos e fisiológicos, que resultarão em morte.
d) de forma direta melhora na absorção de nutrientes principalmente o $\mathbf{P}$ (fósforo).

7. É comum na comunidade microbiana do solo a produção de inibidores metabólicos de grande especificidade e potência, que são utilizados pelo homem como antibióticos, inseticidas e herbicidas com vastas aplicações.

Em qual interação ecológica, determinados micro-organismos do solo produzem essas substâncias?
a) Competição.
b) Parasitismo.
c) Amensalismo.
d) Predadismo.

8. Os micro-organismos do solo decompositores de xenobióticos são, em geral, bactérias pertencentes a vários gêneros, e também fungos e clorófitas. Eucariotos e procariotos degradam os xenobióticos.

Essa capacidade que vários grupos de micro-organismos têm em degradar xenobióticos pode ser usada na biotecnologia para: 
a) melhorar a produção de certas culturas, como por exemplo, a soja que pode ser beneficiada pela decomposição da matéria orgânica da colheita anterior.

b) descontaminar o solo de pesticidas, derivados de petróleo entre outros, melhorando a qualidade do meio ambiente.

c) implementar a produção de alimentos a partir da atividade de certos micro-organismos.

d) diminuir o uso de adubos químicos na agricultura, pois através dos micro-organismos do solo decompositores de xenobióticos ocorre o aumento a fertilidade do solo.

9. No solo existem micro-organismos que são capazes de solubilizar minerais contendo $\mathrm{P}, \mathrm{Ca}, \mathrm{K}, \mathrm{Mg}$ e outros elementos essenciais às plantas, tornando-os disponíveis para o crescimento vegetal. Micro-organismos solubilizadores parecem ser mais abundantes na rizosfera de plantas:

a) por ser uma região rica em diversidade e em densidade microbiana, o que favorece a interação entre as espécies.

b) onde o nível de fosfato é muito baixo, o que favorece os micro-organismos solubilizadores.

c) onde a produção de alimentos é menor devido à baixa atividade de certos micro-organismos.

d) devido o uso de adubos químicos na agricultura, o que pode inibir a atividade desses micro-organismos do solo.

10. Algumas espécies de fungos associam-se às raízes de plantas por serem incapazes de realizar a fotossíntese e, assim, obtêm carbono e outros nutrientes da planta hospedeira. A associação com as raízes torna-se essencial para o ciclo daqueles que não possuem vida saprofílica.

Essas associações são conhecidas como micorrizas, e vários estudos buscam conhecer as bases biológicas desse sistema e seu funcionamento.

\section{Pode-se afirmar como benefícios, exceto:}

a) aumento da produção de plantas em solos marginais.

b) facilidade para recuperação de áreas degradadas e solos contaminados.

c) aumento do índice de nitrogênio no solo através da fixação biológica realizada por esses fungos.

d) redução do uso de insumos químicos principalmente de fertilizante e, assim, contribuir para alcançar uma agricultura mais sustentável e menos dependente de insumos manufaturados. 